\title{
Factorial Validity for the Morale Spirit Scale: The Case for Physical Education Faculty Members in Jordanian Universities
}

\author{
Aman Khasawneh ${ }^{1}$, Ziad Altahayneh ${ }^{1}$, Abedalbasit Abedalhafiz ${ }^{1} \&$ Ahmed A. Okor ${ }^{2}$ \\ ${ }^{1}$ Dept. of Coaching and Sport Management, Faculty of Physical Education and Sport Science, Hashemite \\ University, Zarqa, Jordan \\ ${ }^{2}$ Dept. of Sport Science, Faculty of Physical Education, Yarmouk University, Irbed, Jordan \\ Correspondence: Aman Khasawneh, Faculty of Physical Education and sport Science, The Hashemite University, \\ Zarqa, Jordan. Tel: 962-777-728-000. E-mail: amana752001@yahoo.com
}

Received: February 2, 2015 Accepted: February 28, 2015 Online Published: May 26, 2015

doi:10.5539/res.v7n7p416 URL: http://dx.doi.org/10.5539/res.v7n7p416

\begin{abstract}
This research study has fulfilled the purpose of determining the construction validity of the morale spirit scale (MSS). Ninety faculty members from colleges of physical education at Jordanian universities were chosen to participate in this study. An ex-post facto design is being chosen for this study. The MSS consists of 41 items that measure different dimensions of morale spirit among faculty members. Oblique rotation factoring principle axis was used to disclose instrument's underlying structure. The major findings of this research study revealed six factor solution explaining $72.825 \%$ of common variances. All the six factors were accepted according to the conditions of accepting factors. These six factors were named morale as reflection of faculty and department's administration, the relations between the faculty members, promotions and incentives and salaries, working environment and conditions, regulations and instructions, and the trend toward self and toward the college and university factors.
\end{abstract}

Keywords: factorial validity, morale spirit, faculty members, Jordanian Universities

\section{Introduction}

Faculty retention is an idea that states that faculty members leave their job on any specific reason and thus, it is one of the major challenges to academic institutions (Fabrigar et al., 1999). Competent and qualified faculty members, who are considered an academic asset for higher education institutions, continue to move out from academic institutions despite enormous administrative efforts made to create better working conditions. One reason for such conditions can be due to the morale spirit of faculty members. Morale spirit is a feeling that makes employee satisfied with hishher work, work with enthusiasm, and a positive relationship with his her superiors and integrate with colleagues (Sherritt, 2001). The morale spirit represents the general feeling among individuals that expresses the extent of their happiness and satisfaction with work.

Job satisfaction is one of the factors that contribute to the higher degree of job satisfaction achieved higher morale spirit (Sherritt, 2001). They see administrators as incompetent, communication as poor, and their influence as declining (Boyer et al., 1995). The discontentment, which teachers have with their institutions, is an evident contrast with the courses they teacher, their individual lives and their social interaction within their institutions' social circle (Bowen \& Schuster, 1986; Boyer et al., 1995). Attention to faculty satisfaction is the factor that is included in an examination, other than (Boyer et al., 1995; Olsen, 1993; Olsen et al., 1995), the reduction in the level of morale (Bowen \& Schuster, 1986; Johnsrud \& Rosser, 2002; Kerlin \& Dunlap, 1993), rewards (Boyer, 1990), motivation and productivity (Blackburn \& Lawrence, 1995; Layzell, 1996).

The most important of these factors were salary, stability of work, work conditions, estimates of the work done, fair efficient leadership, available opportunities, harmony with colleagues at work, social status, and important job (Al-Omari, 1990). Evans (2001) sorted the previous factors to financial, psychological, and social factors. Morale can be seen as a three dimensional aspect of job satisfaction that includes mutual loyalty, institutional regard and quality of work (Johnsrud et al., 2000). Studies on faculty morale concluded that faculty members do not have a good level of morale on most American campuses (Bowen \& Schuster, 1986; Rice \& Austin, 1988). According to Bown and Schuster (1986) the low morale was attributed to the following reasons: 
- Deteriorating working conditions.

- Inadequate income.

- Lack of employment mobility.

- Different financial and incentives policies among different colleges.

This debate is confounded by methodological questions by doing analysis, based on proper units (Zeitz, 1989), which is, that should such constructs as morale be analyzed and measured at an individual level, group level, or as a single individual nested within groups. Des Jarlais (1995) stated that "variation in morale was almost entirely related to individuals own perception regardless of their college and academic unit". Conversely, Johnsrud et al. (2000) found that the morale that consist of variation at both individual and institutional levels among midlevel administrators. In 1981, Heath claimed that teachers' morale could be deteriorated because intrinsic motivation and rewards were in decline.

Kerlin and Dunlap (1993) corroborated "the negative impact of inadequate financial resources on faculty morale in a period of austerity and retrenchment. Their findings underscored the adverse impact of declining financial resources coupled with perceptions of inequities within the institution. Findings such as these are not surprising; it is understandable that retrenchment is demoralizing" (Kissler, 1997). In addition the description given by Secor (1995), based on the modern academic department with a lost sense of community, in terms of its common communal purpose and interest is more disheartening. Secor (1995) suggests that the contemporary academic department is more often characterized by politicization around academic issues, ideological stances, growing disrespect between young and old, and intense professional demands that breed tension and distrust. He raises the question as to whether the current demoralized spirit of faculty members has more to do with the intense pressures of their professional lives or with their disillusionment. Many universities made enormous efforts to develop instructors' efficiency and productivity by providing them appropriate conditions, which urge them to increase productivity and raise their levels of motivation through variety of procedures (Abu El-Samen, 1994). However, efforts should to make to raise the morale of employees at all the levels, especially in Jordan. Therefore, purpose of this current study is to construct and validate the Morale Spirit Scale for faculty members in colleges of physical education at Jordanian universities using factorial methodology. However, no research instrument written in Arabic was found to measure the level of morale spirit among faculty members working in colleges of physical education in Jordan (Ary et al., 1996). Hence, the development of adequate constructs for the instrument to be used in the Jordanian University's faculty members, who have an expertise in physical ducation and to validate them is the main purpose of this study.

\section{Method}

\subsection{Study Design}

Survey methodology was used in this study a research design with an ex-post facto. Second semester of the Academic years 2012/2013 served for the development of the MSS and its administration to the faculty members. Exploratory common factor analysis with oblique rotation was used to explore the latent factor of the MSS.

\subsection{Population and Sample}

This study focused on the target population of all faculty members at physical education colleges in Jordanian universities enrolled for the second semester of the academic year 2012/2013. All the sample for this study was based on 90 faculty members from 108, amongst which, 68 were males and 22 females from physical education faculties of Jordanian university. Eighteen faculty members were excluded because of incomplete response.

\subsection{Instrumentation}

This study utilized the MSS developed by researchers. It is a 41-item instrument that measures six domains of morale spirit among faculty members. The constructs for this instrument are morale as reflection of faculty and department's administration domain, the relations between the faculty member's domain, promotions, incentives and salaries domain, working environment and conditions domain, regulations and instructions domain, the trend toward self and toward the college and university domain. All items have been drafted in the positive direction.

\subsubsection{Instrument Constructs Process}

The following processes were used to prepare the instrument of morale spirit scale for faculty members in physical education colleges:

- Review previous educational literature relating to English and Arabic morale spirit studies such as Jawarneh et al., 2011; Kilani, 2010; Awdeh, 2010; Kharfan, 2007; Malkawi, 2006; Rifai, 2006; Zoubi, 1998; Al-Omari, 1990; 
Masaeed, 2004; Abu-El Samen, 1994; Carroll 1993; McGrevin, 1984; Martin, 2000; Redding,1985; Yasaswy, 2001; and Evans, 2001.

- According to the review, 60 items measuring seven domains of morale spirit for faculty members were proposed.

- A panel of experts reviewed the questionnaire to ensure that the items are appropriate to the morale spirit scale and its domains, the extent, linguistic clarity and probity. They were asked to provide any suggestions and make modifications on this instrument.

- Based on the above, the final version of the MSS included 48 items measuring six domains related to morale spirit of faculty members.

- The researchers ensured the scientific transactions for the instrument.

\subsubsection{Instrument Validity}

To ensure the validity of the instrument, a panel on 15 experts reviewed the questionnaire. All experts hold a doctoral degree in different sport and educational fields of study, such as, research design, measurement, evaluation, curriculum, teaching methods, educational administration, and educational psychology. All the experts were requested to review the instrument, identify any items, which were ambiguous in their view, ensure that the items are appropriate to the morale spirit scale and its domains, the extent, linguistic clarity, probity, and make any other comments about the instrument. In the light of their observations the researchers modified, delete, added items, separated and re-drafted some items, return other to the real domain to which they belong, and merged some domains with each other. Thus, their adjustments to the instrument are considered proof of the content validity.

\subsubsection{Instrument Reliability}

To achieve reliability of the instrument, it was applied on 30 faculty members from outside the study sample from colleges of education at Yarmouk, and Jordanian University. The coefficient of Cronbach's alpha was calculated, where the reliability coefficient was 0.85 . This result is considered sufficient for the purposes of this study (Cronbach, 1951).

\subsection{Data Collection Procedures}

Once dean returned the consent forms, researchers arranged a visit to each faculty to administrate all the surveys or acquire an appropriate number of surveys to be given to the head of the departments so that they could administer those surveys according to their personal time of convenience. Surveys were also provided to the head department who viewed them, along with a letter of instruction. Deadlines were provided to head of the departments, who then chose to administer the surveys during regular department meetings. Sample included faculty members, who were responsible for allowing the participation in this research study. All the faculty members voluntarily solicited giving complete justification of their informed will and confidentiality. All the faculty members were requested to sign consent forms, which consisted of further details of this study. The entire data that was collected to conduct this research ensured that complete anonymity shall be maintained by the participants, concerning their details, which are of confidential importance. Questionnaires, consent forms and instructions were given in packets to be delivered on time, following to each department's head, which will have to view the surveys. These department's heads were able to view all the questionnaires in the second semester but before the deadline, which was May 1st, 2013. Once faculty member completed the questionnaires, he delivered it to the department's head and when all questionnaires were completed, they were given back to the researchers.

\subsection{Data Analysis}

Research question was being answered through factor analysis. Exploratory factor analysis is mostly used in the early stages of instrument development especially, when the underlying structure of the instrument is being determined by the researcher. In addition, for the confirmation of the structure of the instrument, Confirmatory factor analysis is used. The technique of exploratory data analysis was more appropriate to use because this is the first time the MSS was used with Jordon population (Ary et al., 1996; Benson \& Nasser, 1998). The objective of exploratory factor analysis (EFA) is to "reduce the number of dimensions necessary to describe the relationships among the variables" (Gardner, 2001). Prediction and data reduction is being done by principal component analysis (Hair et al., 1998; Nunnally \& Bernstein, 1994; Floyd \& Widaman, 1995). The appropriateness of factor analysis was determined by the overall measure of sampling adequacy (MSA) for the whole data set and for individual items. Hair et al. (1998) suggested that "values above 0.90 to be excellent while values below 0.60 
should be deemed unacceptable". The visual screen plot and a given value greater than or equal to one was used to determine the number of factors that are to be extracted (Benson \& Nasser, 1998). The total variance, which is explained by the factor, is represented in this value (Benson \& Nasser, 1998). Once all the factors have been extracted, the next step is to rotate them as an aid in the interpretation of those factors. To obtain a simple structure is the principal goal behind factor rotation (Gorsuch, 1997). In this case, the highest loading on its major factor defines each variable, and the lowest loading on the remaining factors. latent constructs are expected to be correlated in this study, that is why a restriction placed on factors by orthogonal rotation, oblique rotation with direct oblivion was performed (Morgan \& Casper, 2000). When the items had loading above 0.30, they were considered for retention on factors.

In conclusion, following data was reported:

- The entire MSA value for the data to ensure the appropriateness of the data for factor analysis (Morgan \& Casper, 2000).

- The initial, as well as, the ending communalities for all items (after iteration and rotation).

- The overall percentage of variance accounted for by all factors and by each factor separately.

- Each factor's rotated factor loadings.

- Factor correlation matrix.

- Cronbach's alpha was calculated on each of the factors (Cronbach, 1951).

- According to Benson \& Nasser, (1998) “coefficient alphas greater than 0.70 are acceptable for early stages of scale development".

- The standard and mean deviation, including the descriptive statistics on each factor subscales was calculated.

\section{Results}

\subsection{Research Question}

The main research question of this study asks "Will exploratory factor analysis of the MSS result in an interpretable factor structure is consistent with the supposed factors?" Principle axis factoring was performed utilizing the oblique rotation method to disclose the underlying structure of the MSS in Jordan. Data was screened in several ways to ensure their normality and appropriateness to factor analysis before conducting exploratory factor analysis. With respect to normality, visual inspection of the histogram, the mean, median, mode, skewness, and kurtosis for each item, as well as, for the whole data shows that the data was normally distributed. With regard to the appropriateness of this data for factor analysis, two statistical tests (overall Measure of Sampling Adequacy (MSA) and the Bartlett Test of Sphericity) were conducted. An MSA value above 0.70 highlight that there is important variance to explain and that the data are suitable for factor analysis. According to Hair et al. (1998), "an MSA value below 0.60 is considered poor and potentially unacceptable, whereas values above 0.80 are considered meritorious". On the other hand, the Bartlett Test of Sphericity measures the "overall significance of all correlations within a correlation matrix" (Hair et al., 1998). There is no factor structure for the data at hand according to the null hypothesis. Thus, the goal is to reject the null hypothesis. A p-value below 0.05 indicates that there is a factor structure for the data and it is appropriate to run factor analysis. The results of the MSA (.826) and the Bartlett Test of Sphericity $(\mathrm{p}<.05)$ indicated that the data was suitable for factor analysis (Hair et al., 1998). For the justification of the application of factor analysis, it is important to ensure that the correlations of the data matrix for the variables have a substantial number of correlations above 0.30 (Tinsley \& Tinsley, 1987). Visual inspection of the data matrix revealed a substantial number of correlations greater than 0.30 . Finally, there are certain assumptions associated with factor analysis. The faculty member's morale spirit scale asked respondents to reference their responses to morale spirit scale. This instrument contained 48 items. The overall MSA for this section was 0.826 indicating the data was appropriate for factor analysis. Before conducting factor analysis, the MSA value for each item was investigated. The initial analysis was run without specifying how many factors to retain. This procedure resulted in six factors explaining $72.825 \%$ of the common variance. Six-factor solution appeared to provide a conceptual and theoretical representation of morale-spirit scale factors for faculty members in physical education colleges in Jordan Universities. The 6-factor solution explained $72.825 \%$ of the common variance and produced a more meaningful structure. 


\subsubsection{Analysis}

\section{Varible 1: Morale spirit as reflection of faculty and departmne's administration domain}

Questions ranging from 1 to 9 were selected to measure this variable. All the values that were extracted from these nine questions are represented in the chart. Because all the values are higher than 0.5 , it is concluded that they occupy great significance. Amonsgt all the values, highest value is derived out of question 6 that is 0.882 on the other hand, 0.583 is the lowest value of the chart, derived out of question 8 (See Appendix 1). There is high correlation between all the values with variable 1. The Kaiser-Meyer-Olkin and the Bartlett's Test of Sphericity are used to depict the enitre values of all the questions. 0.927 is the overall value and these values can be deemed high and important (See Appendix 2). All these variables were extarcted through effective questions. All those values, which are lower than 0.5 , were quite expected. In order to find out the impact of variable 1 , the chart showing total variance of all the questions have played a significant role. This role has $70 \%$ contribution. The value of total variance is 70.362 , and it is a very good value. One is the variable's Eigenvalue. On the whole, this table portray a very significant link amongst the the varaibles and all the questions, which were asked. Question number 9 shows $100 \%$ value, which are the highest values. On the other hand, question number 1 shows the lowest value, which is 70.362 (See Appendix 3). The value of every single question, in terms of their strong reflection upon the varaible is depicted in the componenet matrix. the chart shows that how clearly variabel is sup ported by each and every question. 0.939 is the highest value shown in question number 6 . On the other hand, 0.764 is the lowest value, which is depicted through question number 8 . On the whole, the entire values are higher than 0.5, which means that each question has supported the variable immensely (See Appendix 4).

\section{Variable 2: The relation between the faculty members domain}

Questions ranging from 10 to 17 were included to measure this variable. However, $17^{\text {th }}$ question is excluded from the data because it depicts values less than 0.5. question number 13 shows highest value in the chart, which is 0.787 . on the other hand, 0.488 is the lowest value in the chart, depicted by question 10 (See Appendix 1). The Kaiser-Meyer-Olkin and the Bartlett's Test of Sphericity depicts the entire values, extracted by all the questions. 0.857 is the overall value. This is a high and a very significant value. Questions used to find this variable were asked very effectively (See Appendix 2). $60 \%$ of findings of the effect of variable 2 is supported by the questions. This is depicted in the chart of total variance. 2 is the variable's Eigenvalue. On the whole, this table portray a very significant link amongst the the varaibles and all the questions, which were asked. $100 \%$ value is extracted from question number 7, which is the highest value. On the other hand, 60.798 is the lowest value extracted from question number 1 (See Appendix 3). The value of every single question, in terms of their strong reflection upon the varaible is depicted in the componenet matrix. the chart shows that how clearly variabel is supported by each and every question. 0.887 is the highest value shown in question number 13. On the other hand, 0.698 is the lowest value, which is depicted through question number 10 (See Appendix 4).

\section{Varible 3: Promotion and incentives and salaries domain}

Questions ranging from 18 to 24 were included to measure this variable. Question number 24 shows highest value in the chart, which is 0.851 on the other hand, 0.620 is the lowest value in the chart, depicted by question 18 (See Appendix 1). The Kaiser-Meyer-Olkin and the Bartlett's Test of Sphericity depict the entire values, extracted by all the questions. 0.838 is the overall value. This is a high and a very significant value. Questions used to find this variable were asked very effectively (See Appendix 2). $74 \%$ of findings of the effect of variable 3 is supported by the questions. This is depicted in the chart of total variance. On the whole, this table portray a very significant link amongst the the varaibles and all the questions, which were asked. $100 \%$ value is extracted from component 5 , which is the highest value. On the other hand, 74.731 is the lowest value extracted from component 1 (See Appendix 3). The value of every single question, in terms of their strong reflection upon the varaible is depicted in the componenet matrix. the chart shows that how clearly variabel is supported by each and every question. 0.992 is the highest value shown in question number 24 . On the other hand, 0.787 is the lowest value, which is depicted through question number 18 (See Appendix 4).

\section{Variable 4: Working environment and condition domain}

Questions ranging from 25 to 32 were included to measure this variable. However, question 29 and 30 were excluded from the data because of having very low value. Question number 26 shows highest value in the chart, which is 0.883 . On the other hand, 0.534 is the lowest value in the chart, depicted by question 28 . The chart depicts these questions (See Appendix 1). The Kaiser-Meyer-Olkin and the Bartlett's Test of Sphericity depicts the entire values, extracted by all the questions. 0.855 is the overall value. This is a high and a very significant value. Questions used to find this variable were asked very effectively (See Appendix 2). $70 \%$ of findings of the effect of variable 4 is supported by the questions. This is depicted in the chart of total variance. On the whole, 
this table portray a very significant link amongst the the varaibles and all the questions, which were asked. $100 \%$ value is extracted from component 5 , which is the highest value. On the other hand, 70.533 is the lowest value extracted from component 1 (See Appendix 3). The value of every single question, in terms of their strong reflection upon the varaible is depicted in the componenet matrix. the chart shows that how clearly variabel is supported by each and every question. 0.913 is the highest value shown in question number 26 . On the other hand, 0.731 is the lowest value, which is depicted through question number 28 (See Appendix 4).

\section{Varibles 5: Regulation and instrucation domain}

Questions ranging from 33 to 40 were included to measure this variable. However, question 34 is excluded from the data because of having value less than 5. Question number 37 shows highest value in the chart, which is 0.757 . On the other hand, 0.565 is the lowest value in the chart, depicted by question 35 . The chart depicts these questions (See Appendix 1). The Kaiser-Meyer-Olkin and the Bartlett's Test of Sphericity depicts the entire values, extracted by all the questions. 0.890 is the overall value. This is a high and a very significant value. Questions used to find this variable were asked very effectively (See Appendix 2). 66\% of findings of the effect of variable 5 is supported by the questions. This is depicted in the chart of total variance. On the whole, this table portray a very significant link amongst the the varaibles and all the questions, which were asked. $100 \%$ value is extracted from component 7, which is the highest value. On the other hand, 60.723 is the lowest value extracted from component 1 (See Appendix 3). The value of every single question, in terms of their strong reflection upon the varaible is depicted in the componenet matrix. the chart shows that how clearly variabel is supported by each and every question. 0.870 is the highest value shown in question number 37 . On the other hand, 0.752 is the lowest value, which is depicted through question number 35 (See Appendix 4).

\section{Variable 6: The trend toward self and toward the college and university domain}

Questions ranging from 41 to 48 were included to measure this variable. However, question $42^{\text {nd }}$ is excluded from the data because of having very low value. Question number 44 shows highest value in the chart, which is 0.640 . On the other hand, 0.307 is the lowest value in the chart, depicted by question 41 . The chart depicts these questions (See Appendix 1). The Kaiser-Meyer-Olkin and the Bartlett's Test of Sphericity depicts the entire values, extracted by all the questions. 0.796 is the overall value. This is a high and a very significant value. Questions used to find this variable were asked very effectively (See Appendix 2). 53\% of findings of the effect of variable 6 is supported by the questions. This is depicted in the chart of total variance. On the whole, this table portray a very significant link amongst the varaibles and all the questions, which were asked. $100 \%$ value is extracted from component 7, which is the highest value. On the other hand, 53.399 is the lowest value extracted from component 1 (See Appendix 3). The value of every single question, in terms of their strong reflection upon the varaible is depicted in the componenet matrix. the chart shows that how clearly variable is supported by each and every question. 0.800 is the highest value shown in question number 44 . On the other hand, 0.554 is the lowest value, which is depicted through question number 41 (See Appendix 4).

\section{Discussion}

Results of the factor analysis indicated that six latent factors with 41 items emerged from MSS. Factor analysis of MSS completed in this study identified a six-factor solution as the most acceptable multiple dimension representation of the data.The six factors identified were morale as reflection of faculty and department's administration factor, the relations between the faculty member's factor, promotions and incentives and salaries factor, working environment and conditions, regulations and instructions factor, and the trend toward self and toward the college and university factor.

Results suggest that the MSS can provide reliable and internally consistent measurement for morale spirit for faculty members in Jordanian universities. These results are consistent with other cross-cultural instrument validation research done with the MSS. For example, Assaf and Assaf (2007) validated the MSS with the same factor analysis procedures and resulted in validation of the first five factors; those factors that conducted in a similar way as the factors in this study.

\section{Recommendations for Future Research}

This research study is aimed at improving the psychometric qualities of certain MSS scales. The numbers of items on few of the factors should be increased. Those writing items that have negative connotations should be avoided. Definition of each construct in Jordonian University should be validated by its faculty members by using various methods, including, focus groups, interviews and surveys. In addition, after the enhancement of the structure of the MSS, a confirmatory factor analysis (CFA) should be utilized to completely confirm the latent structure of the MSS. The items found should belong to a certain factor in the initial exploratory factor analysis 
and this thing should be confirmed by CFA methodology. After this confirmation, MSS should be explored with a different sample to ensure that the factor structure exists in the Jordanian culture. Thirdly, criterion validity of the MSS in Jordan should be established by making its linkage with other important outcomes in learning process. All the methods will add credibility to the measuring instrument and will also establish criterion validity.

\section{References}

Abu-El Samen, M. (1994). The impact of educational factors selected in the degree of morale among secondary school teachers in the province of Al-Balqa (Unpublished Master Thesis). University of Jordan, Amman, Jordan.

Al-Omari, A. (1990). Obstacles school decision-making and its relationship to morale at the secondary school teachers in Jordan (Unpublished Master Thesis). Yarmouk University, Irbid, Jordan.

Ary, D., Jacob, L., \& Razavieh, A. (1996). Introduction to research in education (5th ed.). Fort Worth, TX: Harcourt Brace College Publishers.

Assaf, A., \& Assaf, H. (2007). Morale levels and its sources among teachers of lower primary stage in the city of Nablus (Palestine). Najah University Journal for Research: Humanities, 21(3), 37-51.

Awdeh, H. (2010). Administrative competencies for primary schools administrators in Madaba and its relationship to the morale of teachers (Unpublished Master Thesis). University of the Middle East, Jordan.

Benson, J., \& Nasser, F. (1998). On the use of factor analysis as a research tool. Journal of Vocational Education Research, 23(1), 13-33.

Blackburn, T., \& Lawrence, H. (1995). Faculty at work: Motivation, expectation, satisfaction. Baltimore: The Johns Hopkins University Press.

Bowen, R., \& Schuster, H. (1986). American professors: A national resource imperiled. New York: Oxford University Press.

Boyer, L. (1990). Scholarship reconsidered: Priorities of the professoriate. Princeton, NJ: Carnegie Foundation for the Advancement of Teaching.

Boyer, L., Altbach, G., \& Wihitelaw, J. (1995). The academic profession: An international perspective. San Francisco: Jossey-Bass.

Carroll, O. (1993). Teacher moral as related to school leadership behavior (Moral Leadership Behavior). Dissertation Abstracts International, 54(7), 382.

Cronbach, J. (1951). Coefficient alpha and the internal structure of tests. Psychometrika, 16, $297-334$. http://dx.doi.org/10.1007/BF02310555

Dse Jarlais, D. (1995). Determinants of faculty morale in an American public research university: Gender differences within and between academic departments (Unpublished doctoral dissertation). University of Hawai'i at Manoa.

Evans, L. (2001). Delving deeper into morale, job satisfaction and motivation among education professionals: Rexamine the leadership dimension. Educational Management and Administration, 29, 291-306.

Fabrigar, R., Wegener, T., Maccallum, C., \& Strahan, J. (1999). Evaluating the use of exploratory factor analysis in psychological research. Psychological Methods, 4(3), 272-299. http://dx.doi.org/10.1037/1082-989X.4.3.272

Floyd, J., \& Widaman, F. (1995). Factor analysis in the development and refinement assessment instruments. Psychological Assessment, 7(3), 286-299. http://dx.doi.org/10.1037/1040-3590.7.3.286

Gardner, C. (2001). Psychological statistics using SPSS for windows. Upper Saddle River, NJ: Prentice-Hall, Inc.

Gorsuch, L. (1997). Exploratory factor analysis: Its role in item analysis. Journal of Personality Assessment, 68(3), 532-560. http://dx.doi.org/10.1207/s15327752jpa6803_5

Hair, F., Anderson, E., Tatham, L., \& Black, C. (1998). Multivariate data analysis (5th ed.). Englewood Cliffs, NJ: Prentice Hall.

Heath, D. (1981). Faculty Burnout, Morale, and Vocational Adaptation. National Association of Independent Schools. 18 Tremont St., Boston.

Jawarneh, M., Khasawneh, A., Khasawneh, S., \& Edaeis, A. (2011). The degree of morale among teachers in the primary stage in the province of Zarqa and its relationship with some variables. Journal of Educational 
Sciences, 38(2), 62-78.

Johnsrud, K., Heck, H., \& Rosser, J. (2000). Morale matters: Midlevel administrators and their intent to leave. Journal of Higher Education, 71, 34-59. http://dx.doi.org/10.2307/2649281

Johnsrud, K., \& Rosser, J. (2002). Faculty member's morale and their intention to leave. Journal of Higher Education, 73(4), 518-541. http://dx.doi.org/10.1353/jhe.2002.0039

Kerlin, P., \& Dunlap, M. (1993). For richer, for poorer: Faculty morale in periods of austerity and retrenchment. Journal of Higher Education, 64, 348-377. http://dx.doi.org/10.2307/2959931

Kharfan, R. (2007). Work relations in the public Jordanian universities and its relation to morale and job performance of faculty members (Unpublished doctoral dissertation). Amman Arab University, Jordan.

Kilani, L. (2010). The roles of schools administrators in improving the organization environment and its relationship to the morale of teachers (Unpublished Master Thesis). Amman Arab University, Jordan.

Kissler, R. (1997). Who decides which budgets to cut? Journal of Higher Education, 68, $427-459$. http://dx.doi.org/10.2307/2960011

Layzell, T. (1996). Faculty workload and productivity: Recurrent issues with new imperatives. Review of Higher Education, 19, 267-281.

Malkawi, N. (2006). The effectiveness of colleges boards in Jordanian universities and their relation to morale and personal relationships for faculty members (Unpublished doctoral dissertation). Amman Arab University for Graduate Studies, Jordan.

Martin, W. (2000). A Study of the relationship between elementary principal leadership behaviour and teacher moral. Dissertation Abstract International, 61(2), 2128.

Masaeed, A. (2004). The level of supervision practices of the educational supervisors and its relationship with educational competencies and morale of teachers in the primary stage in Jordan (Unpublished doctoral dissertation). Amman Arab University for Graduate Studies, Amman, Jordan.

Mcgrevin, Z. (1984). Teacher participation in the decision-making process and its relationship to organizational commitment and moral. Dissertation Abstract International, 45(5), 1258.

Morgan, B., \& Casper, J. (2000). Examining the factor structure of participant reactions to training: A multidimensional approach. Human Resource Development Quarterly, 11(3), 301-317. http://dx.doi.org/10.1002/1532-1096

Nunnally, C., \& Bernstein, H. (1994). Psychometric theory. New York: Mc Graw Hill.

Olsen, D. (1993). Work satisfaction and stress in the first and third year of academic appointment. Journal of Higher Education, 64, 453-471. http://dx.doi.org/10.2307/2960052

Olsen, D., Maple, A., \& Stage, K. (1995). Woman and minority faculty job satisfaction. Journal of higher education, 66(3), 267-293. http://dx.doi.org/10.2307/2943892

Redding, J. (1985). Perception of catholic secondary school teachers and principals about decision-making and the effect on teacher moral. Dissertation Abstract International, 45(7), 1947.

Rice, R., \& Austin, E. (1988). Faculty morale: What exemplary colleges do right change? Dissertation Abstract International, 20(2), 51-58.

Rifai, N. (2006). The degree of morale among teachers of Islamic Education in the public schools and its relation of their student's achievement in Jordan (Unpublished doctoral dissertation). Amman Arab University for Graduate Studies, Jordan.

Secor, R. (1995). Recapturing departmental community: A tale of faculty morale, external pressures and departmental collaboration. $A A H E, 3-6$.

Sherritt, A. (2001). Industrial Psychology: Foundations and applications. Cairo, Egypt: Modern University Office.

Tinsley, E., \& Tinsley, J. (1987). Uses of factor analysis in counseling psychology research. Journal of Counseling Psychology, 34(4), 414-424. http://dx.doi.org/10.1037/0022-0167.34.4.414

Yasaswy, G. (2001). Human Resource Management Text and Cases (2nd ed.). New Delhi: Excel Books.

Zeitz, G. (1989). Structural and individual determination of organizational morale and satisfaction. Social Force, 61(4), 1088-1108. 
Zoubi, F. (1998). Study the level of satisfaction and morale of Mutah University staff. Mutah for Research and Studies, 13(1), 135-153.

\section{Appendix 1}

\section{Communalities of the six variables}

\begin{tabular}{|c|c|c|c|}
\hline & \multicolumn{3}{|c|}{ Communalities } \\
\hline \multirow{2}{*}{$\begin{array}{l}\text { Variable 1: Morale Spirit as Reflection of Faculty and } \\
\text { Department's Administration Domain }\end{array}$} & \multirow[b]{2}{*}{ q1 } & \multirow{2}{*}{$\begin{array}{l}\text { Initial } \\
1.000\end{array}$} & \multirow{2}{*}{$\begin{array}{l}\text { Extraction } \\
.774\end{array}$} \\
\hline & & & \\
\hline & q2 & 1.000 & .595 \\
\hline & $\mathrm{q} 3$ & 1.000 & .763 \\
\hline & $\mathrm{q} 4$ & 1.000 & .612 \\
\hline & q5 & 1.000 & .716 \\
\hline & q6 & 1.000 & .882 \\
\hline & q7 & 1.000 & .787 \\
\hline & q8 & 1.000 & .583 \\
\hline & q9 & 1.000 & .621 \\
\hline \multirow{7}{*}{$\begin{array}{l}\text { Variable 2: The Relations between the Faculty } \\
\text { Members Domain }\end{array}$} & $\mathrm{q} 10$ & 1.000 & .488 \\
\hline & q11 & 1.000 & .693 \\
\hline & $\mathrm{q} 12$ & 1.000 & 601 \\
\hline & $\mathrm{q} 13$ & 1.000 & .787 \\
\hline & q14 & 1.000 & .617 \\
\hline & $\mathrm{q} 15$ & 1.000 & .494 \\
\hline & q16 & 1.000 & .576 \\
\hline \multirow[t]{5}{*}{ Variable 3: Promotions and Incentives and Salaries Domain } & q18 & 1.000 & 620 \\
\hline & q19 & 1.000 & .792 \\
\hline & $\mathrm{q} 22$ & 1.000 & .709 \\
\hline & q23 & 1.000 & .765 \\
\hline & $\mathrm{q} 24$ & 1.000 & .851 \\
\hline \multirow[t]{5}{*}{ Variable 4: Working Environment and Conditions Domain } & $\mathrm{q} 25$ & 1.000 & .728 \\
\hline & q26 & 1.000 & .833 \\
\hline & $\mathrm{q} 27$ & 1.000 & .787 \\
\hline & q28 & 1.000 & .534 \\
\hline & $\mathrm{q} 31$ & 1.000 & .644 \\
\hline \multirow{7}{*}{ Variable 5: Regulations and Instructions Domain } & $\mathrm{q} 33$ & 1.000 & .582 \\
\hline & $\mathrm{q} 35$ & 1.000 & .565 \\
\hline & $\mathrm{q} 36$ & 1.000 & .755 \\
\hline & $\mathrm{q} 37$ & 1.000 & .757 \\
\hline & $\mathrm{q} 38$ & 1.000 & .729 \\
\hline & q39 & 1.000 & 680 \\
\hline & $\mathrm{q} 40$ & 1.000 & .603 \\
\hline Variable 6: The Trend toward Self and Toward the College and & $\mathrm{q} 41$ & 1.000 & .307 \\
\hline \multirow[t]{6}{*}{ University Domain } & $\mathrm{q} 43$ & 1.000 & .514 \\
\hline & $\mathrm{q} 44$ & 1.000 & .640 \\
\hline & $\mathrm{q} 45$ & 1.000 & .493 \\
\hline & $\mathrm{q} 46$ & 1.000 & .632 \\
\hline & q47 & 1.000 & .580 \\
\hline & $\mathrm{q} 48$ & 1.000 & .571 \\
\hline
\end{tabular}




\section{Appendix 2}

KMO and Bartlett's Test of the variables

KMO and Bartlett's Test of variable 1: Morale Spirit as Reflection of Faculty and Department's Administration Domain

\begin{tabular}{lll}
\hline Kaiser-Meyer-Olkin Measure of Sampling Adequacy. & .927 \\
& Approx. Chi-Square & 699.485 \\
Bartlett's Test of Sphericity & Df & 36 \\
& Sig. & .000
\end{tabular}

KMO and Bartlett's Test of variable 2: The Relations between the Faculty Members Domain

Kaiser-Meyer-Olkin Measure of Sampling Adequacy. $\quad .857$

\begin{tabular}{lll} 
& Approx. Chi-Square & 335.256 \\
Bartlett's Test of Sphericity & Df & 21 \\
& Sig. & .000 \\
\hline
\end{tabular}

KMO and Bartlett's Test of Variable 3: Promotions and Incentives and Salaries Domain

$\begin{array}{ll}\text { Kaiser-Meyer-Olkin Measure of Sampling Adequacy. } & .838\end{array}$

$\begin{array}{lll} & \text { Approx. Chi-Square } & 327.502 \\ \text { Bartlett's Test of Sphericity } & \text { Df } & 10 \\ & \text { Sig. } & .000\end{array}$

KMO and Bartlett's Test of variable 4: Working Environment and Conditions Domain

Kaiser-Meyer-Olkin Measure of Sampling Adequacy. $\quad .855$

Approx. Chi-Square $\quad 271.172$

$\begin{array}{lll}\text { Bartlett's Test of Sphericity } & \text { Df } & 10\end{array}$

Sig. $\quad .000$

KMO and Bartlett's Test of Variable 5: Regulations and Instructions Domain

Kaiser-Meyer-Olkin Measure of Sampling Adequacy. $\quad .890$

Approx. Chi-Square 406.392

$\begin{array}{lll}\text { Bartlett's Test of Sphericity } & \text { Df } & 21\end{array}$

Sig. $\quad .000$

KMO and Bartlett's Test of variable 6: The Trend toward Self and Toward the College and University Domain

Kaiser-Meyer-Olkin Measure of Sampling Adequacy. $\quad .796$

\begin{tabular}{lll} 
& Approx. Chi-Square & 329.975 \\
Bartlett's Test of Sphericity & Df & 21 \\
& Sig. & .000 \\
\hline
\end{tabular}

\section{Appendix 3}

Total Variance Explained of the variables

Total Variance Explained of the variable 1: Morale Spirit as Reflection of Faculty and Department's Administration Domain

\begin{tabular}{lllllll}
\hline Component & \multicolumn{2}{l}{ Initial Eigenvalues } & & \multicolumn{3}{c}{ Extraction Sums of Squared Loadings } \\
& Total & \% of Variance & Cumulative\% & Total & \% of Variance & Cumulative \% \\
1 & 6.333 & 70.362 & 70.362 & 6.333 & 70.362 & 70.362
\end{tabular}




$\begin{array}{llll}2 & .781 & 8.681 & 79.042 \\ 3 & .467 & 5.192 & 84.235 \\ 4 & .342 & 3.798 & 88.033 \\ 5 & .287 & 3.185 & 91.218 \\ 6 & .258 & 2.867 & 94.085 \\ 7 & .235 & 2.610 & 96.694 \\ 8 & .198 & 2.195 & 98.890 \\ 9 & .100 & 1.110 & 100.000\end{array}$

\begin{tabular}{lllllll}
\hline \multicolumn{3}{l}{$\begin{array}{l}\text { Total Variance Explained of the variable 2: The Relations between the Faculty Members Domain } \\
\text { Component }\end{array}$} & \multicolumn{5}{l}{$\begin{array}{l}\text { Initial Eigenvalues } \\
\text { Extraction Sums of Squared Loadings }\end{array}$} \\
\hline & Total & \% of Variance & Cumulative \% & Total & \% of Variance & Cumulative \% \\
1 & 4.256 & 60.798 & 60.798 & 4.256 & 60.798 & 60.798 \\
2 & .750 & 10.717 & 71.515 & & & \\
3 & .617 & 8.809 & 80.324 & & \\
4 & .573 & 8.180 & 88.504 & & \\
5 & .341 & 4.871 & 93.375 & & \\
6 & .269 & 3.849 & 97.224 & & \\
7 & .194 & 2.776 & 100.000 & & & \\
\hline
\end{tabular}

\begin{tabular}{lllllll}
\multicolumn{3}{l}{$\begin{array}{l}\text { Total Variance Explained of the variable 3: The Relations between the Faculty Members Domain } \\
\text { Component }\end{array}$} & \multicolumn{5}{l}{ Initial Eigenvalues } \\
\hline & Total & \% of Variance & Cumulative \% & Total & \% of Variance & Cumulative \% \\
1 & 3.737 & 74.731 & 74.731 & 3.737 & 74.731 & 74.731 \\
2 & .525 & 10.501 & 85.232 & & & \\
3 & .363 & 7.266 & 92.498 & & & \\
4 & .245 & 4.909 & 97.407 & & \\
5 & .130 & 2.593 & 100.000 & & & \\
\hline
\end{tabular}

Total Variance Explained of the variable 4: working environment and condition domain

\begin{tabular}{lllllll} 
Component & \multicolumn{2}{l}{ Initial Eigenvalues } & \multicolumn{3}{l}{ Extraction Sums of Squared Loadings } \\
\hline & Total & \% of Variance & Cumulative \% & Total & \% of Variance & Cumulative \% \\
1 & 3.527 & 70.533 & 70.533 & 3.527 & 70.533 & 70.533 \\
2 & .574 & 11.487 & 82.020 & & & \\
3 & .451 & 9.023 & 91.043 & & & \\
4 & .274 & 5.486 & 96.529 & & & \\
5 & .174 & 3.471 & 100.00 & & & \\
\hline
\end{tabular}

\begin{tabular}{lllllll}
\hline \multicolumn{3}{l}{$\begin{array}{l}\text { Total Variance Explained of the variable 5: regulations and instructions domain } \\
\text { Component }\end{array}$} & \multicolumn{5}{c}{ Initial Eigenvalues } \\
\hline & Total & \% of Variance & Cumulative \% & Total & \% of Variance & Cumulative \% \\
1 & 4.671 & 66.723 & 66.723 & 4.671 & 66.723 & 66.723 \\
2 & .647 & 9.245 & 75.968 & & & \\
3 & .589 & 8.418 & 84.385 & & & \\
4 & .374 & 5.338 & 89.724 & & & \\
5 & .295 & 4.216 & 93.940 & &
\end{tabular}




$\begin{array}{llll}6 & .228 & 3.261 & 97.200 \\ 7 & .196 & 2.800 & 100.000\end{array}$

\section{Total Variance Explained of the variable 6:}

\begin{tabular}{lllllll} 
Component & \multicolumn{2}{l}{ Initial Eigenvalues } & \multicolumn{3}{c}{ Extraction Sums of Squared Loadings } \\
\hline & Total & \% of Variance & Cumulative \% & Total & \% of Variance & Cumulative \% \\
1 & 3.738 & 53.399 & 53.399 & 3.738 & 53.399 & 53.399 \\
2 & 1.299 & 18.558 & 71.957 & & \\
3 & .776 & 11.081 & 83.038 & & \\
4 & .460 & 6.570 & 89.608 & & \\
5 & .338 & 4.822 & 94.430 & & \\
6 & .232 & 3.321 & 97.751 & & \\
7 & .157 & 2.249 & 100.000 &
\end{tabular}

\section{Appendix 4}

\section{Component Matrix for the variables}

\begin{tabular}{|c|c|c|}
\hline Variables & Items & Component \\
\hline \multirow{9}{*}{$\begin{array}{l}\text { Variable 1: Morale Spirit as Reflection of Faculty and Department's } \\
\text { Administration Domain }\end{array}$} & q1 & .880 \\
\hline & $\mathrm{q} 2$ & .771 \\
\hline & q3 & .874 \\
\hline & $\mathrm{q} 4$ & .782 \\
\hline & q5 & .846 \\
\hline & q6 & .939 \\
\hline & $\mathrm{q} 7$ & .887 \\
\hline & q8 & .764 \\
\hline & q9 & .788 \\
\hline \multirow[t]{8}{*}{ Variable 2: The Relations between the Faculty Members Domain } & q10 & .698 \\
\hline & q11 & .833 \\
\hline & q12 & .775 \\
\hline & q13 & .887 \\
\hline & q14 & .785 \\
\hline & q15 & .703 \\
\hline & q16 & .759 \\
\hline & q10 & .698 \\
\hline \multirow[t]{5}{*}{ Variable 3: Promotions and Incentives and Salaries Domain } & q18 & .787 \\
\hline & q19 & .890 \\
\hline & $\mathrm{q} 22$ & .842 \\
\hline & $\mathrm{q} 23$ & .874 \\
\hline & q24 & .922 \\
\hline \multirow[t]{4}{*}{ Variable 4: Working Environment and Conditions Domain } & $\mathrm{q} 25$ & .853 \\
\hline & $\mathrm{q} 26$ & .913 \\
\hline & $\mathrm{q} 27$ & .887 \\
\hline & q28 & .731 \\
\hline
\end{tabular}




\begin{tabular}{lcc} 
& $\mathrm{q} 31$ & .803 \\
\hline Variable 5: Regulations and Instructions Domain & $\mathrm{q} 33$ & .763 \\
& $\mathrm{q} 35$ & .752 \\
& $\mathrm{q} 36$ & .869 \\
& $\mathrm{q} 37$ & .870 \\
Variable 6: The Trend toward Self and Toward the College and University & $\mathrm{q} 41$ & .854 \\
Domain & $\mathrm{q} 38$ & .825 \\
& $\mathrm{q} 39$ & .776 \\
\hline & $\mathrm{q} 43$ & .717 \\
& $\mathrm{q} 44$ & .800 \\
& $\mathrm{q} 45$ & .702 \\
\hline
\end{tabular}

\section{Copyrights}

Copyright for this article is retained by the author(s), with first publication rights granted to the journal.

This is an open-access article distributed under the terms and conditions of the Creative Commons Attribution license (http://creativecommons.org/licenses/by/3.0/). 